\title{
Prussian Blue based screen printed biosensors with improved characteristics of long-term lifetime and $\mathrm{pH}$ stability
}

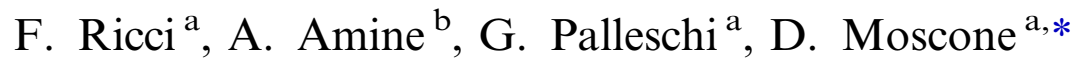 \\ a Dipartimento di Scienze e Tecnologie Chimiche, Università 'Tor Vergata', Rome 00133, Italy \\ ${ }^{\mathrm{b}}$ Facultè de Sciences et Techniques, Universitè Hassan II-Mohammadia, Mohammadia, Morocco
}

Received 5 October 2001; accepted 28 March 2002

\begin{abstract}
The promising advantages of Prussian Blue (PB) as catalyst and of the thick film screen printing technology have been combined to assemble sensors with improved characteristics for the amperometric determination of $\mathrm{H}_{2} \mathrm{O}_{2}$. PB-modified screen printed electrodes were applied to detect $\mathrm{H}_{2} \mathrm{O}_{2}$ at an applied potential of $-0.05 \mathrm{~V}$ versus the internal screen printed Ag pseudoreference electrode, showing a detection limit of $10^{-7} \mathrm{~mol} 1^{-1}$, a linearity range from $10^{-7}$ to $5 \times 10^{-5} \mathrm{~mol} 1^{-1}$, a sensitivity of $234 \mu \mathrm{A}$ mmol $1^{-1} \mathrm{~cm}^{-2}$, and a high selectivity. Improved stability at alkaline $\mathrm{pH}$ values was also observed, which made possible their use with enzymes having an optimum basic $\mathrm{pH}$. Then, the immobilisation of a single enzyme (glucose oxidase (GOD) or choline oxidase $(\mathrm{ChOX}))$ or of two enzymes, acetylcholinesterase (AchE) coimmobilised with ChOX, has been performed on the surface of PB modified screen-printed electrodes (SPEs) using glutaraldehyde and Nafion ${ }^{\circledR}$. ChOX has been selected as an example of enzyme working at alkaline $\mathrm{pH}$. The choline biosensors showed a detection limit of $5 \times 10^{-7} \mathrm{~mol} 1^{-1}$, a wide linearity range $\left(5 \times 10^{-7}-\right.$ $10^{-4}$ mol $1^{-1}$ ), a high selectivity and a remarkable long term stability of 9 months at $4{ }^{\circ} \mathrm{C}$, and at least 4 weeks at room temperature. Similar analytical characteristics and stability were observed with the acetylcholine biosensors.
\end{abstract}

(C) 2002 Elsevier Science B.V. All rights reserved.

Keywords: Prussian Blue; Screen printed electrodes; $\mathrm{H}_{2} \mathrm{O}_{2}$ determination; Oxidase biosensors

\section{Introduction}

In the field of enzyme electrode probes, the most widely used enzymes belong to the family of oxidases. A product of the reaction catalysed by these enzymes is the hydrogen peroxide, and its electroactivity has been utilised to obtain a measurable current signal. Usually the electrochemical determination of $\mathrm{H}_{2} \mathrm{O}_{2}$ is accomplished by its oxidation at noble metal electrodes such as $\mathrm{Pt}$ and $\mathrm{Au}$, although the required voltage is often sufficiently high to also oxidise other interfering compounds and/or organic molecules, which may be present in the sample.

Carbon electrodes can offer an inexpensive alternative to $\mathrm{Pt}$, having in addition attractive features as a wide anodic potential range, low electrical resistance and low

* Corresponding author. Fax: +39-06-202-4342

E-mail address: moscone@uniroma2.it (D. Moscone). residual current. Moreover, they exist in a variety of forms as glassy carbon, carbon fibres, graphite pastes and carbon films (Gilmartin and Hart, 1995). Unfortunately, these electrodes require a high overpotential to detect $\mathrm{H}_{2} \mathrm{O}_{2}$ (Iannello and Iacynych, 1981), further reducing the selectivity of the sensors.

Many efforts have been made to improve the selectivity of carbon based electrochemical sensors, mainly through their modification with redox mediators (Cass et al., 1984; Frew and Hill, 1987).

Numerous other approaches have also been tested, such as the use of metallised ( $\mathrm{Rh}, \mathrm{Ru}$ ) carbons to allow the non-mediated oxidation of $\mathrm{H}_{2} \mathrm{O}_{2}$ at a low applied potential (White et al., 1996; Newman et al., 1995) and electrode modification with peroxidase (HRP; Gorton, 1995).

In addition, the modification of electrodes with Prussian Blue (PB) has been particularly effective in enhancing the selectivity towards oxidase enzyme substrates. 
In the last years in fact, $\mathrm{PB}$ or ferric ferrocyanide $\left(\mathrm{Fe}_{4}^{\mathrm{III}}\left[\mathrm{Fe}^{\mathrm{II}}(\mathrm{CN})_{6}\right]_{3}\right)$ has been the subject of studies by many research groups involved in the optimisation of amperometric biosensors. This growing interest was due to the peculiar characteristic of the reduced form of $\mathrm{PB}$, Prussian White, to catalyse the reduction of $\mathrm{H}_{2} \mathrm{O}_{2}$ (Neff, 1978; Itaya et al., 1982) at low applied potential, around $0.0 \mathrm{~V}$ versus $\mathrm{Ag} / \mathrm{AgCl}$. In this way, the effect of the most common electrochemical interfering species is avoided or greatly reduced. The inorganic nature of $\mathrm{PB}$ and its low cost makes it more suitable than HRP in assembling modified biosensors. PB modified glassy carbon (Itaya et al., 1984; Karyakin et al., 1996, 1998), graphite (Chi and Dong, 1995; Jaffari and Turner, 1997; Deng et al., 1998), carbon paste (Garjonyte and Malinauskas, 1998) and platinum (Itaya et al., 1982) electrodes have been studied, leading to the construction of glucose (Karyakin et al., 1995; Garjonyte and Malinauskas, 2000), lactate (Garjonyte et al., 2001), glutamate (Karyakin et al., 2000), aminoacid (Chi and Dong, 1995) and alcohol (Karyakin et al., 1996) biosensors. Recently, a review on the analytical applications of $\mathrm{PB}$ has appeared in literature (Karyakin, 2001).

The use of $\mathrm{PB}$ as catalyst for $\mathrm{H}_{2} \mathrm{O}_{2}$ reduction is still a matter of concern because of its poor operational stability, limited to a range of hours, and to a very high decrease in sensitivity at neutral and alkaline $\mathrm{pH}$.

During recent years the screen printing (thick film) technology applied to sensor and biosensor construction has been considerably improved and a large number of papers, and recently some reviews, have appeared in the literature (Hart and Wring, 1997; Albareda-Silvert et al., 2000). Screen-printed electrodes (SPEs) are in fact inexpensive, simple to prepare, rapid and versatile and this technology appears to be also the most economical mean for large-scale production of disposable electrodes.

Until now, just two papers have dealt with the modification of SPEs by hexacyanoferrates. The first is based on the dispersion of an analogue of PB, the cupric-hexacyanoferrate, and glucose oxidase (GOD) within the carbon ink (Wang and Zhang, 1999). The resulting glucose biosensor showed a good selectivity with regard to the common electrochemical interferences, but at physiological $\mathrm{pH}$ the signal decreased by $10 \%$ after $2 \mathrm{~h}$.

The second paper (O'Halloran et al., 2001) is based on the bulk modification of the carbon ink by PB microparticles $(<38 \mu \mathrm{m})$. The PB-SPEs show low detection limits $\left(0.4 \mu \mathrm{mol} \mathrm{l}^{-1}\right)$ and a sensitivity of $137 \mu \mathrm{A} \mathrm{mmol}$ $1^{-1} \mathrm{~cm}^{-2}$ for $\mathrm{H}_{2} \mathrm{O}_{2}$ and, when modified as glucose biosensor, a linear range up to $3 \mathrm{mmol} \mathrm{l}^{-1}$ of glucose, with no interferences. However, $\mathrm{pH}$ stability experiments, performed with the PB-modified SPEs, revealed again a decrease of the $\mathrm{H}_{2} \mathrm{O}_{2}$ amperometric signal $(50 \%$ of the initial activity after $4 \mathrm{~h}$ of continuous use) at $\mathrm{pH}$ values above 7 .

Recently, we reported a new method of graphite powder modification with 'in situ' chemically synthesised $\mathrm{PB}$, which resulted in a very active and very stable matrix suitable for the construction of PB modified carbon paste and solid carbon paste electrodes (where solid paraffin replaces mineral oil in the paste; Moscone et al., 2001).

In this work, we report the results obtained by applying this new method of PB deposition to SPEs in order to assemble PB based biosensors. Our modified SPEs exhibit high sensitivity, good reproducibility and $\mathrm{pH}$ stability, yielding selective measurements of $\mathrm{H}_{2} \mathrm{O}_{2}$ in a synthetic mixture of electroactive substances.

Moreover, we report a new procedure of enzyme immobilisation on the PB modified SPEs, which shows both improved storage lifetime and operational stability. This procedure has been tested with immobilised GOD first, then with choline oxidase (ChOX), selected as an example of enzyme working at alkaline $\mathrm{pH}$ (Keesey, 1987) and finally with the coimmobilisation of two enzymes, ChOX and acetylcholinesterase (AchE).

The biosensors assembled with the SPEs have been designed to be reused, rather than to be disposable. Several examples of screen-printed biosensors principally inserted as detectors in flow injection systems can be found in literature (White et al., 1996; Rippeth et al., 1997; Tothill et al., 1997; Collier et al., 1998).

\section{Experimental}

\subsection{Reagents}

All chemicals from commercial source were of analytical grade.

Glutaraldehyde $25 \%$ (v/v), Nafion ${ }^{\circledR} 5 \%(\mathrm{v} / \mathrm{v})$, bovine serum albumin (BSA), acetonitrile $(99.5 \%)$ and Triton X-100 ( $t$-octylphenoxypoly-ethoxyethanol), GOD from Aspergillus niger VII S (195 $\mathrm{U} \mathrm{mg}^{-1}$ ) (E.C. 1.1.3.4) and AchE from Electric Eel. Type VI S (200-400 U mg ${ }^{-1}$ ) (E.C. 3.1.1.7) were from Sigma.

ChOX from Alcaligenes spp. (11.7 $\left.\mathrm{U} \mathrm{mg}^{-1}\right)$ (E.C. 1.1.3.17) was by Fluka.

Unless otherwise stated, all solutions were prepared with $0.05 \mathrm{~mol}^{-1}$ phosphate buffer $+0.1 \mathrm{~mol}^{-1} \mathrm{KCl}$, $\mathrm{pH}$ 7.4. Standard solutions were daily prepared in the same buffer.

\subsection{Apparatus}

Amperometric measurements were carried out in batch using a VA 641 amperometric detector (Metrohm, Herisau, Switzerland), connected to a X-t recorder (L250E, Linseis, Selb, Germany). 
Cyclic voltammetry experiments were performed with an Autolab electrochemical system (Eco-Chemie, Utrecht, Netherlands) equipped with PGSTAT 12 and GPES software.

The orbital shaker was from MPM Instruments (Bernareggio, Mi, Italy).

\subsection{Electrodes}

SPEs were obtained from the Biosensors laboratory of the University of Florence (Italy).

Electrodes were printed with a 245 DEK (Weymouth, UK) screen printing machine, and using different inks obtained from Acheson Italiana (Milan, Italy). Graphite-based ink (Electrodag 421) silver ink (Electrodag 477 SS RFU) and insulating ink (Electrodag 6018 SS) were used. The substrate was a polyester flexible film (Autostat HT5) obtained from Autotype Italia (Milan, Italy). The printing procedure utilised is already described in previous papers (Cagnini et al., 1995; Hernandez et al., 2000). They were produced in foils of 20 strips, each containing three printed electrodes, a carbon working and two silver electrodes, acting as pseudoreference and counter, respectively. The diameter of the working electrode was $0.3 \mathrm{~cm}$, which resulted in an apparent geometric area of $0.07 \mathrm{~cm}^{2}$.

\subsection{Electrode pre-treatment}

Prior PB modification, SPEs were pre-treated in a $0.05 \mathrm{~mol} \mathrm{l}^{-1}$ phosphate buffer $+0.1 \mathrm{~mol} \mathrm{l}^{-1} \mathrm{KCl}, \mathrm{pH}$ 7.4 , by applying an anodic potential of $1.7 \mathrm{~V}$ for different periods (from $20 \mathrm{~s}$ to $4 \mathrm{~min}$ ).

All the applied potentials mentioned in the paper are referred to the internal $\mathrm{Ag}$ pseudoreference electrode of the SPEs.

\subsection{Prussian Blue deposition}

PB modification of SPEs was accomplished by placing a drop (40 $\mu$ l of total volume) of precursor solutions onto the working electrode area. This solution is a mixture obtained 'in loco' adding $20 \mu \mathrm{l}$ of $0.1 \mathrm{~mol}^{-1}$ potassium ferricyanide $\left(\mathrm{K}_{3} \mathrm{Fe}(\mathrm{CN})_{6}\right)$ in $10 \mathrm{mmol}^{-1}$ $\mathrm{HCl}$ to $20 \mu \mathrm{l}$ of $0.1 \mathrm{~mol} \mathrm{l}^{-1}$ ferric chloride in $10 \mathrm{mmol}$ $1^{-1} \mathrm{HCl}$. The drop was carefully placed exclusively on the working electrode area, in order to avoid the formation of $\mathrm{PB}$ on the reference and counter electrodes that could notably increase the internal resistance of the system. The electrodes were gently shaken on an orbital shaker for $10 \mathrm{~min}$ and then rinsed with few millilitres of $10 \mathrm{mmol} 1^{-1} \mathrm{HCl}$. The probes were then left $1 \mathrm{~h}$ in the oven at $100{ }^{\circ} \mathrm{C}$ to obtain a more stable and active layer of $\mathrm{PB}$.

The PB modified electrodes were stored dry at room temperature in dark.

\subsection{Enzyme immobilisation}

Choline and GOD were immobilised onto the PBmodified electrode surface with the cross-linking method. A mixture of glutaraldehyde, Nafion ${ }^{\circledR}$, enzyme and BSA was used.

To prepare $150 \mu \mathrm{l}$ of this mixture, $20 \mu \mathrm{l}$ of glutaraldehyde $(2.5 \% \mathrm{v} / \mathrm{v}$ diluted in water) and $30 \mu \mathrm{l}$ of Nafion ${ }^{\circledR}(5 \% \mathrm{v} / \mathrm{v}$ in ethanol) were mixed with $100 \mu 1$ of a solution prepared dissolving $40 \mathrm{mg}$ of BSA and 10 $\mathrm{mg}$ of enzyme in $1 \mathrm{ml}$ of $0.05 \mathrm{~mol}^{-1}$ phosphate buffer $+0.1 \mathrm{~mol} \mathrm{l}^{-1} \mathrm{KCl}, \mathrm{pH} 7.4$.

The above mixture $(7 \mu \mathrm{l})$ was placed onto the working electrode area and allowed to dry for $45 \mathrm{~min}$ at room temperature, then the electrodes were washed for $30 \mathrm{~min}$ with a solution of $0.1 \mathrm{~mol} \mathrm{l}^{-1}$ glycine to saturate all the free aldehydic groups.

When the acetylcholine biosensor was prepared, the AchE enzyme was coimmobilised together with the choline oxidase enzyme. In this case, the whole procedure was the same, the only difference being in the enzymatic solution, which contained $30 \mathrm{mg}$ BSA, $10 \mathrm{mg}$ ChOX, and $10 \mathrm{mg}$ of AchE dissolved in $1 \mathrm{ml}$ of working buffer.

\subsection{Electrode characterisation with cyclic voltammetry}

The optimisation of the pre-treatment procedure was performed recording cyclic voltammograms in a ferricyanide buffer solution $\left(0.05 \mathrm{~mol} \mathrm{l}^{-1}\right.$ phosphate +0.1 mol $1^{-1} \mathrm{KCl}, \mathrm{pH}$ 7.4). Once deposited, the PB layer was studied cycling in a range of potential between -0.5 and $+1.2 \mathrm{~V}$, with a scan rate of $50 \mathrm{mV} \mathrm{s}^{-1}$ in above mentioned buffer solution.

\section{8. $\mathrm{H}_{2} \mathrm{O}_{2}$ and enzymatic substrate measurements}

$\mathrm{H}_{2} \mathrm{O}_{2}$ and enzymatic substrates (i.e. glucose, choline and acetylcholine) were measured dipping the electrode in $10 \mathrm{ml}$ of a stirred phosphate buffer at an applied potential of $-0.05 \mathrm{~V}$ versus screen printed internal silver pseudoreference electrode. When a stable current background was reached $(30-60 \mathrm{~s})$, the analyte was added and the response was measured after $30 \mathrm{~s}$.

\section{Results and discussion}

To assemble oxidase-based biosensors, several optimisations were performed in order to obtain a reliable $\mathrm{H}_{2} \mathrm{O}_{2}$-PB based screen-printed sensor. To achieve this objective, the first step has been the pre-treatment and electrochemical characterisation of the electrode strips. 


\subsection{Optimisation of the pretreatment procedure}

It is reported that electrochemical pretreatments of SPEs can improve their electrochemical behaviour (Wang et al., 1996). In order to obtain a more reproducible and active surface, the electrodes were polarised at $1.7 \mathrm{~V}$ for different periods (in a range between $20 \mathrm{~s}$ and $4 \mathrm{~min}$ ) and the effect of this oxidation was evaluated by cyclic voltammetry in a ferricyanide solution. The increase of the total oxidation time up to 3 min resulted in a better electrochemical behaviour: the $\Delta E_{\mathrm{p}}$ was lowered from 520 to $150 \mathrm{mV}$ and the peak currents were doubled (Fig. 1). Then, a time of 3 min at $1.7 \mathrm{~V}$ has been chosen as the best compromise to achieve a consistent improvement of the SPEs electrochemical performances in the shortest time. In fact, no further improvements were observed with 4 min of oxidation.

The application of this anodic potential gave also a better interelectrode reproducibility. The R.S.D.\% of the $i_{\text {pa }}$ (anodic peak current) obtained with eight electrodes was in fact lowered from a value of $10 \%$ (before pretreatment) to $5 \%$ (after pretreatment). In the case of the $i_{\mathrm{pc}}$ (cathodic peak current), the R.S.D. $\%$ was $17 \%$ for the non-pretreated electrodes and 5\% after the pretreatment.

\section{2. $P B$ modified electrode characterisation}

The deposition of PB on different substrates is usually accomplished by the electrochemical reduction of an equimolar mixture of ferric and ferricyanide ions (Itaya et al., 1982, 1984; Chi and Dong, 1995; Karyakin et al., 1998; Zhang et al., 1999; Garjonyte and Malinauskas,

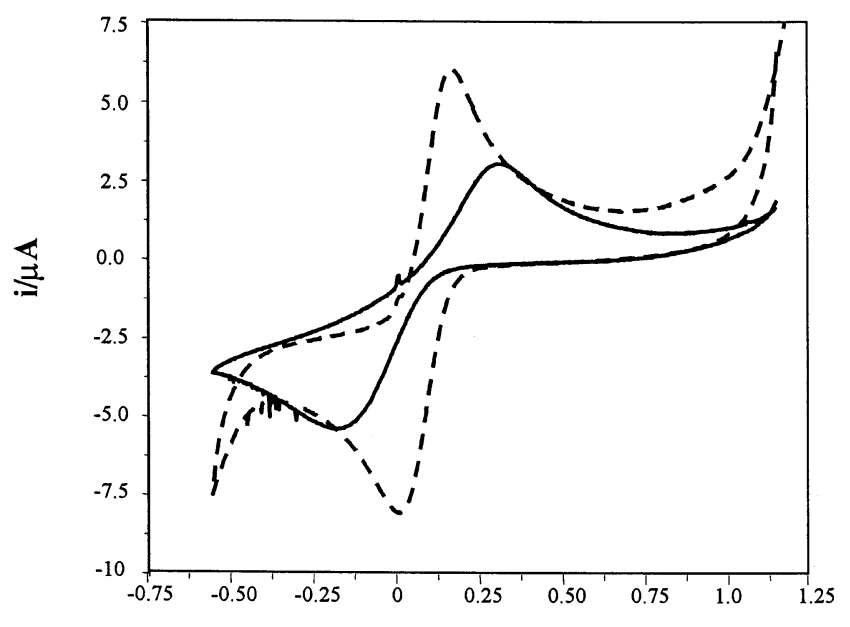

E/V

Fig. 1. Cyclic voltammograms of $1 \mathrm{mmol}^{-1} \mathrm{~K}_{3} \mathrm{Fe}(\mathrm{CN})_{6}$ in $0.05 \mathrm{~mol}$ $1^{-1}$ phosphate buffer $+0.1 \mathrm{~mol} \mathrm{l}^{-1} \mathrm{KCl}$, pH 7.4 of a non-treated screen printed electrode (solid line) and a treated ( $3 \mathrm{~min}$ at $1.7 \mathrm{~V}$ vs. $\mathrm{Ag} / \mathrm{AgCl}$ ) screen printed electrode (dashed line). Potential range $=-$ 0.6 to $1.2 \mathrm{~V}$. Scan rate $=50 \mathrm{mV} \mathrm{s}^{-1}$.
2000). In addition, non-electroplating methods can be applied (Neff, 1978; Weißenbacher et al., 1992; Zakharchuk et al., 1995; Garjonyte and Malinauskas, 1998), but in this case they seem to be highly dependent from the nature of the substrate surface itself (Itaya et al., 1982).

In our previous work (Moscone et al., 2001), we successfully applied the latter procedure by chemical synthesis of PB onto graphite powder particles, obtaining a very effective modified matrix. The carbon ink used for the SPEs printing process is obtained by mixing graphite and other different compounds, such as polymeric binders and solvents in order to improve its viscosity. Due to this evident difference in the electrode composition, the achievement of good results as those obtained for the graphite powder was not obvious. For example, the same procedure applied to conventional solid glassy carbon electrodes, resulted in a very poor deposition of $\mathrm{PB}$, which completely disappeared during cyclic voltammetry after only few scans (data not shown).

The effectiveness of the PB deposition procedure onto the SPEs was verified by cycling the modified electrodes from -0.5 to $1.2 \mathrm{~V}$. Fig. 2 shows the voltammograms of the bare SPE and of the PB-modified SPE. In the latter case, the typical two pairs of redox waves showing the oxidation as well as the reduction of PB are present. Moreover, the increase of the cathodic wave at around $0.1 \mathrm{~V}$ in presence of $\mathrm{H}_{2} \mathrm{O}_{2}$ can also be noticed, proving the activity of the catalyst on the electrode.

PB modified SPEs represent the support for enzyme immobilisation: their performances in respect of $\mathrm{H}_{2} \mathrm{O}_{2}$ response (detection limit, linearity range, and reprodu-

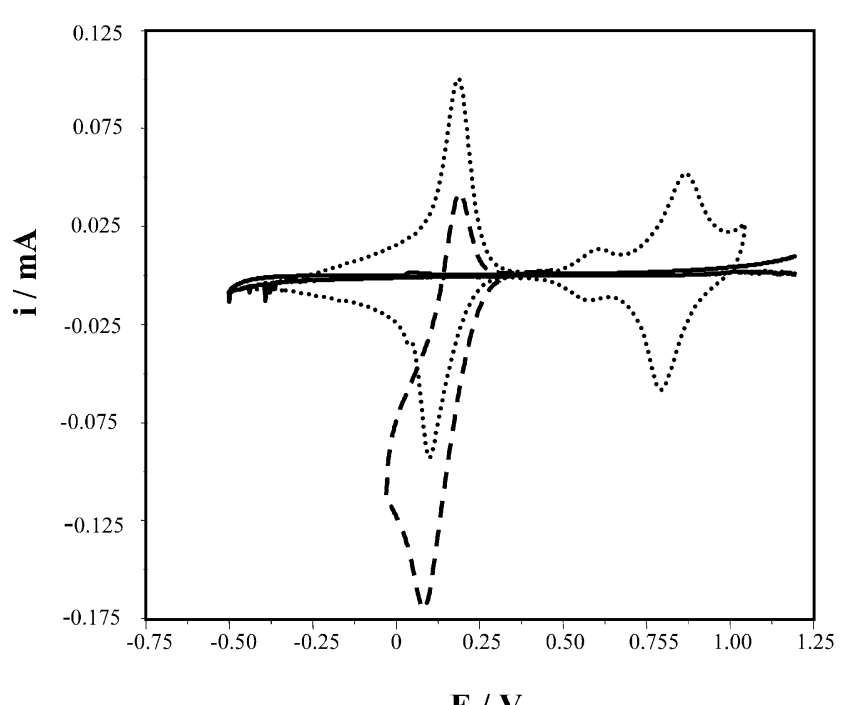

$\mathbf{E} / \mathbf{V}$

Fig. 2. Cyclic voltammograms $(-0.5$ to $1.2 \mathrm{~V})$ in $0.05 \mathrm{~mol}^{-1}$ phosphate buffer $+0.1 \mathrm{~mol}^{-1} \mathrm{KCl}$, pH 7.4 of bare SPE (continuous line); PB-modified SPE (dotted line); PB-modified SPE in presence of $\mathrm{H}_{2} \mathrm{O}_{2} 10 \mathrm{mmol} \mathrm{l}^{-1}$ (dashed line; in this case the voltammogram was carried out between -0.05 and $0.35 \mathrm{~V}$ ). Scan rate $50 \mathrm{mV} \mathrm{s}^{-1}$. 
cibility) were then carefully studied. Before this, the $\mathrm{pH}$ effect was evaluated and the best potential for $\mathrm{H}_{2} \mathrm{O}_{2}$ reduction was chosen, as illustrated below.

\section{3. $p H$-effect}

Cyclic voltammetry was also performed to evaluate the electrochemical behaviour and the stability of the PB layer to $\mathrm{pH}$ changes.

Fig. 3 shows cyclic voltammograms between -0.2 and $+0.4 \mathrm{~V}$ (scan rate $50 \mathrm{mV} \mathrm{s}^{-1}$ ) in buffer solutions at different $\mathrm{pH}$ values. Only the first cycle and the 250th one are depicted.

At $\mathrm{pH} 3$ we obtained the best stability of $\mathrm{PB}$ in accordance of what reported in literature (Itaya et al., 1984; Garjonyte and Malinauskas, 1998, 1999; Zhang et al., 1999).

At $\mathrm{pH} 7$, the $\mathrm{PB}$ layer is still well bound on the electrode surface and we can observe just a slight decrease of the peak current values after 250 cycles.

It has also to be stressed how the modified electrode behaves at $\mathrm{pH}$ 9. Although at this $\mathrm{pH}$ the $\mathrm{PB}$ layer deposited on the electrode surface shows a lower stability, after 250 cycles is still highly electroactive and sufficient to catalyse the $\mathrm{H}_{2} \mathrm{O}_{2}$ reduction. In fact, amperometric measurements of $\mathrm{H}_{2} \mathrm{O}_{2}\left(10 \mu \mathrm{mol} 1^{-1}\right)$ were carried out before and after the continuous cycling at $\mathrm{pH} 9$, and the decrease of the signal was only $10 \%$ of the initial value.

The operational stability of all the PB modified sensors is a critical point, especially at neutral and alkaline $\mathrm{pH}$. A possible explanation could be the presence of hydroxyl ions at the electrode surface as a product of the $\mathrm{H}_{2} \mathrm{O}_{2}$ reduction. The hydroxyl ions are known to be able to break the $\mathrm{Fe}-\mathrm{CN}-\mathrm{Fe}$ bond, hence solubilizing the PB (Karyakin, 2001). In our opinion, the good results here achieved, similar to those observed in a previous paper (Moscone et al., 2001), are due to the proposed method of deposition, which involves the chemical synthesis of PB in the presence of graphite, allowing its capillary adsorption. Moreover, the SPEs anodization pretreatment carried out at $1.7 \mathrm{~V}$ could produce carboxylic groups similar to those produced with aqua regia on graphite powder in our mentioned previous work, and the presence of these groups seems to contribute to the formation of PB films (Jaffari and Turner, 1997). In addition, recently has been demonstrated that electrochemical pretreatments induce some cracking of the surface of the carbon electrodes with the increase of its effective working area (Grennan et al., 2001). For all these reasons, a larger and deeper absorption of $\mathrm{PB}$ is probably obtained, and the carbon surface acts as a reservoir of well-bound $\mathrm{PB}$, which minimises the leakage due to the hydrolysis of ferric ions, and increases the operational stability even at alkaline $\mathrm{pH}$.

These PB modified electrodes could, therefore, be used also with enzymes having an optimum alkaline $\mathrm{pH}$.

\subsection{Selection of the applied potential}

The choice of the applied potential at the working electrode is fundamental to achieve the lowest detection limit and to avoid the electrochemical interfering species. $\mathrm{H}_{2} \mathrm{O}_{2}$ and ascorbic acid, both at a concentration of $0.1 \mathrm{mmol}^{-1}$ were measured at five different values of potential near $0.0 \mathrm{~V}$ (Fig. 4). The ascorbic acid gave an oxidation signal, while the signal due to $\mathrm{H}_{2} \mathrm{O}_{2}$ resulted in a reduction. The optimum potential was $50 \mathrm{mV}$ because of the highest signal for $\mathrm{H}_{2} \mathrm{O}_{2}$ and the low interference from ascorbic acid (only $2 \%$ of the ratio ascorbic acid $/ \mathrm{H}_{2} \mathrm{O}_{2} \times 100$ ). In spite of the similar interference/signal ratio, a higher current background was obtained at $-100 \mathrm{mV}$.

Moreover, at the selected potential of $-50 \mathrm{mV}$, the time necessary to reach a stable background current was as low as $30-60 \mathrm{~s}$. a)

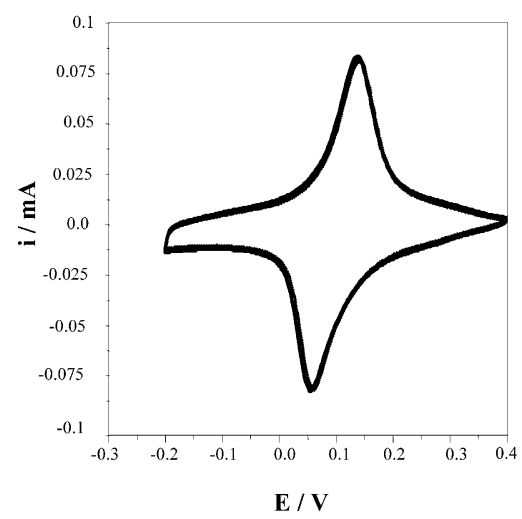

b)

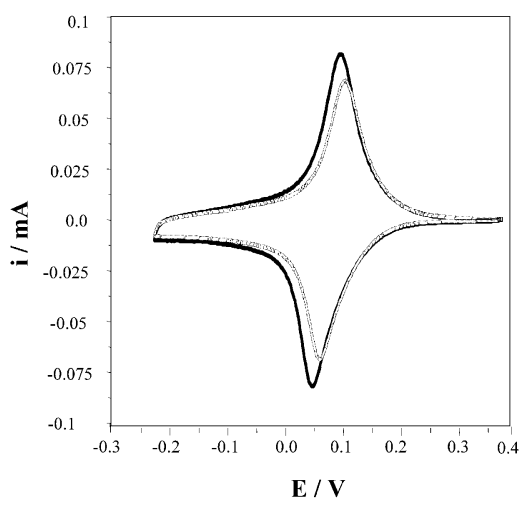

c)

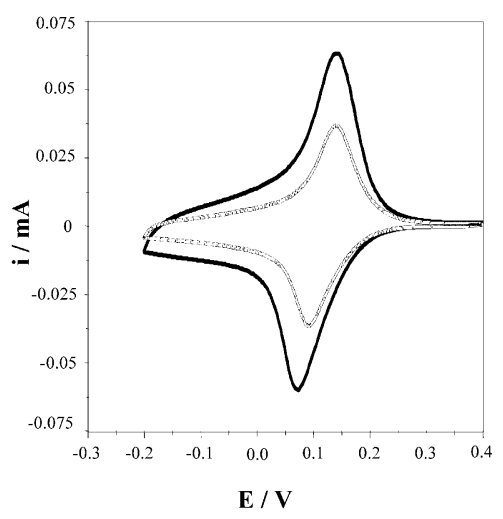

Fig. 3. Cyclic voltammograms in $0.05 \mathrm{~mol}^{-1}$ phosphate buffer at (a) $\mathrm{pH} 3$; (b) $\mathrm{pH} 7$; (c) $\mathrm{pH}$ 9. Solid lines represent the first cycle of a series of 250 continuous cycling. The dashed lines are the 250 th of the same series. Potential range $=-0.2$ to $0.4 \mathrm{~V}$. Scan rate $50 \mathrm{mV} \mathrm{s}^{-1}$. 


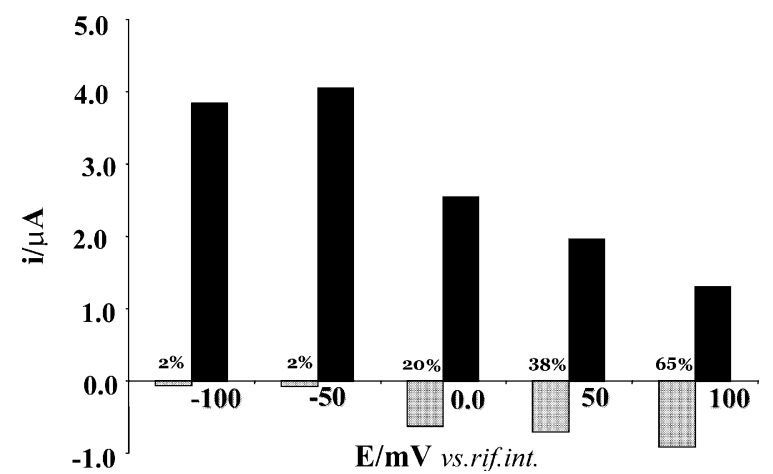

Fig. 4. Response of the PB-modified SPEs to $\mathrm{H}_{2} \mathrm{O}_{2}$ in 0.05 mol $1^{-1}$ phosphate buffer $+0.1 \mathrm{~mol}^{-1} \mathrm{KCl}, \mathrm{pH} \mathrm{7.4}$, at different applied potential; grey bars: $0.1 \mathrm{mmol} 1^{-1}$ ascorbic acid (oxidation current); black bars: $0.1 \mathrm{mmol} 1^{-1} \mathrm{H}_{2} \mathrm{O}_{2}$ (reduction current).

\subsection{PB modified electrode performances}

PB-electrodes were then studied using cyclic voltammetry in a range between -0.2 and $+0.4 \mathrm{~V}$ at different scan rates (in a range between 2 and $200 \mathrm{mV} \mathrm{s}^{-1}$ ). A linear correlation between the scan rate and the current peaks (both anodic and cathodic) has been observed in a range between 2 and $50 \mathrm{mV} \mathrm{s}^{-1}$, as expected in the case of an adsorbed electroactive substance on the electrode surface.

Then PB modified electrodes have been tested as $\mathrm{H}_{2} \mathrm{O}_{2}$ probes, and response time, detection limit, linearity range, sensitivity and electrode reproducibility were studied. All the measurements were performed in a 0.05 mol $1^{-1}$ phosphate buffer $+0.1 \mathrm{~mol}^{-1} \mathrm{KCl}, \mathrm{pH} 7.4$ and at an applied potential of $-0.05 \mathrm{~V}$.

The $\mathrm{H}_{2} \mathrm{O}_{2}$ calibration curves obtained with six different electrodes (using each electrode for all the concentration values tested) showed a good linearity in a range between 0.1 and $50 \mu \mathrm{mol} 1^{-1}$ with a detection limit of $0.1 \mu \mathrm{mol} 1^{-1}$. Fig. 5 shows the calibration curve together with the representation of few authentic responses in the micromolar range. The regression equation of the linear part of the curve was $y=22.90 x-0.013$, where $y$ represents the current in $\mu \mathrm{A}$ and $x$ the $\mathrm{H}_{2} \mathrm{O}_{2}$ concentration in $\mathrm{mmol}^{-1}$; the $R^{2}$ was 0.9980 . The sensitivity was $324 \mu \mathrm{A} \mathrm{mmol} 1^{-1} \mathrm{~cm}^{-2}$, and the R.S.D. $\%$ was up to $5 \%$ (for all the concentrations tested by six different electrodes). The response time needed to reach $90 \%$ of the steady state response was $30 \mathrm{~s}$.

The electrodes were also tested in hydro-organic solvent (working buffer/acetonitrile ratio: 60/40 v/v) and in buffer containing Triton X-100 1\% (m/v). No variation in the response to the addition of $\mathrm{H}_{2} \mathrm{O}_{2}(10$ $\mu \mathrm{mol} 1^{-1}$ ) was found after dipping the modified SPE in buffer/acetonitrile solution for $48 \mathrm{~h}$. The same behaviour was observed after $48 \mathrm{~h}$ in the Triton solution.

\subsection{Enzymatic substrate measurements}

The results obtained with the PB modified SPEs brought us to investigate their possible use in the assembling of oxidase enzyme based biosensors. Scheme 1 gives an overview of the reactions involved.

The PB-modified electrodes were then used as support for the oxidase enzyme immobilisation. The planar characteristics of sensors produced by screen-printed technology require a good and reproducible contact between the enzymatic layer and the working electrode as well as a good robustness of this layer onto the electrodic area.

Several experiments have been carried out to obtain a stable and active enzymatic layer. Nafion ${ }^{\circledR}$ and glutaraldehyde were used for this purpose. GOD was selected for the optimisation of the immobilisation procedure.

Preliminary experiments were carried out using enzymatic solutions and Nafion. Different enzyme amounts ranging from 0.75 to $150 \mathrm{U} \mathrm{ml}^{-1}$ were placed on the electrode surface, fixed with different Nafion ${ }^{\circledR}$ solutions $(0.5-5 \% \mathrm{v} / \mathrm{v})$ and tested. In all cases, no steady state signal was observed probably because of a not complete entrapment of the enzyme by the Nafion ${ }^{\circledR}$. In fact, no response to the substrate was obtained when electrodes were reused.

A glutaraldehyde cross-linking method was then tested to obtain a more stable layer. Also in this case different enzymatic solutions $\left(0.2-50 \mathrm{mg} \mathrm{ml}^{-1}\right)$ were mixed with different glutaraldehyde solutions $(0.25-5 \%$ $\mathrm{v} / \mathrm{v})$. The resulting membranes were also unstable because a spontaneous detachment under stirring conditions was observed.

The combination of the crosslinking proprieties of glutaraldehyde with the ability of Nafion ${ }^{\circledR}$ to fix the enzymatic membrane on the carbon surface of the working electrode solved this problem. This novel optimised procedure, described in the Section 2 resulted in a strong improvement of the membrane stability together with a high enzymatic activity.

Under our experimental conditions, the PB-modified screen-printed glucose biosensors showed a linearity range between 2 and $100 \mu \mathrm{mol} 1^{-1}$, and a detection limit of $1 \mu \mathrm{mol} 1^{-1}$. The linear regression equation was: $y=4.4 x-0.005$ where $y$ represents the current in $\mathrm{nA}$ and $x$ the glucose concentration in $\mu \mathrm{mol}^{-1}$; the $R^{2}$ was 0.9989 . The calibration curves were repeated using five different biosensors and a R.S.D. $\%$ up to $5 \%$ was obtained. The sensitivity was $63 \mu \mathrm{Ammol} 1^{-1} \mathrm{~cm}^{-2}$, and the enzymatic efficiency, i.e. the response of glucose in respect to the same concentration of hydrogen peroxide, measured with the same electrode, was about $32 \%$.

The stability of the PB layer at basic $\mathrm{pH}$ brought us to investigate the use of $\mathrm{PB}$ modified electrodes with oxidase enzymes having an alkaline optimum $\mathrm{pH}$. For 


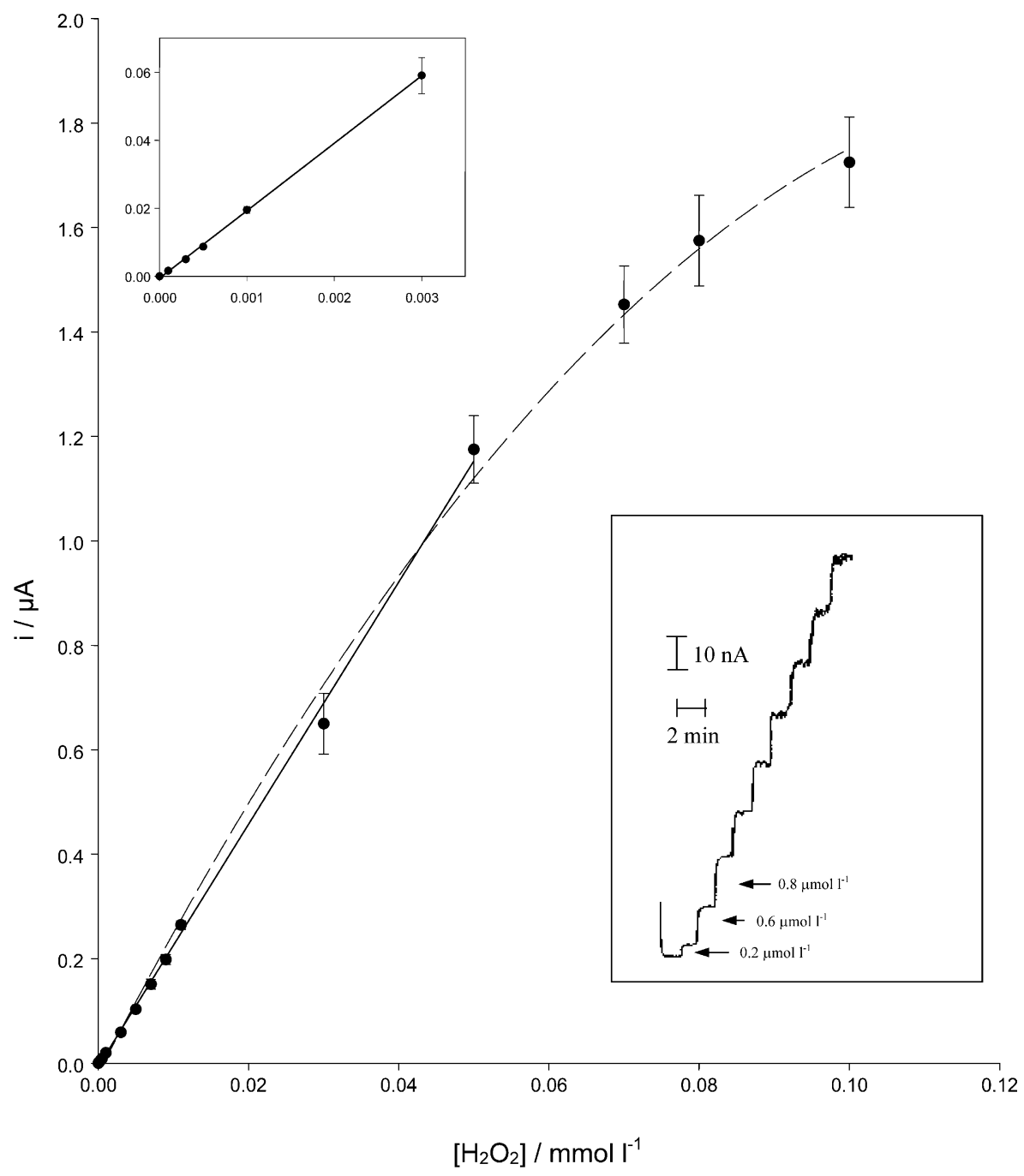

Fig. 5. $\mathrm{H}_{2} \mathrm{O}_{2}$ calibration curve obtained with $\mathrm{PB}$ modified $\mathrm{SPE}(n=6)$. In the lower insert, the actual response curve for some $\mathrm{H}_{2} \mathrm{O}_{2}$ additions is also shown. All the additions successive to the second one are of the same entity $\left(0.8 \mu \mathrm{mol} 1^{-1}\right)$. Applied potential $-50 \mathrm{mV}$ vs. the internal Ag pseudoreference electrode.

$$
\begin{array}{lc}
\mathrm{E}_{\text {app }} \approx 0.0 \mathrm{~V} . & \text { Sensory } \\
\text { vs. } \mathrm{Ag} / \mathrm{AgCl} & \text { interface }
\end{array}
$$

Bulk solution

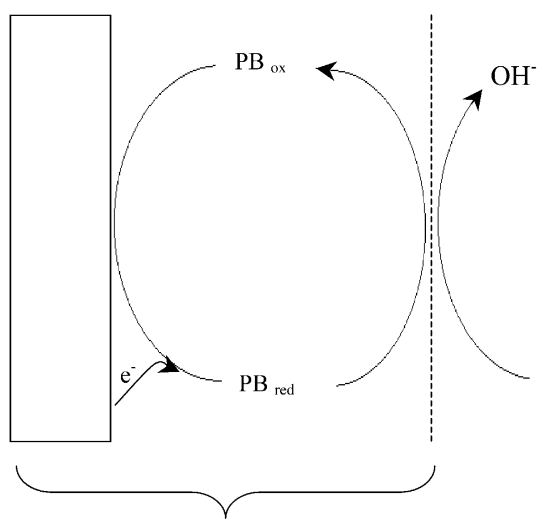

PB modified

Screen printed electrode

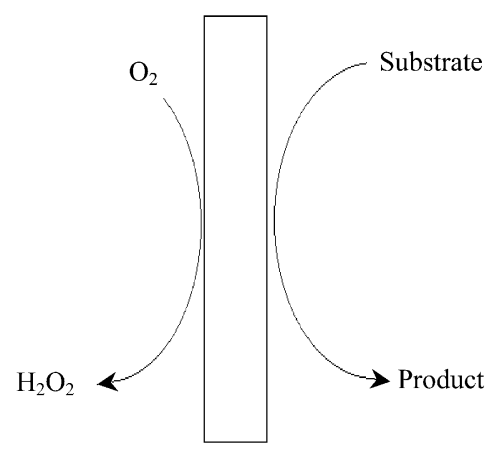

Enzymatic membrane and Nafion

Scheme 1. General overview for an oxidase PB modified electrode. 
this reason, choline oxidase was immobilised on the PBelectrode surface using the same procedure, and the analytical properties of these screen printed biosensors were studied.

\subsubsection{Choline biosensor}

Choline biosensors were then tested to define the detection limit, linearity range, sensitivity and reproducibility. Calibration curves were obtained with six biosensors, (for each biosensor all the concentration values were measured) and the analytical parameters were as follows: linear range between 0.5 and $100 \mu \mathrm{mol}$ $1^{-1}$; detection limit $0.5 \mu \mathrm{mol} 1^{-1}$, R.S.D. $\%$ up to $6 \%$. The equation of the linear regression was: $y=7.7 x-$ 0.04 where $y$ represents the current in $\mathrm{nA}$ and $x$ the choline concentration in $\mu \mathrm{mol} 1^{-1}$. The $R^{2}$ was 0.9949 , and the sensitivity $110 \mu \mathrm{A} \mathrm{mmol} 1^{-1} \mathrm{~cm}^{-2}$. Since the enzymatic activity increased with the $\mathrm{pH}$ up to a maximum plateau of $\mathrm{pH} \mathrm{7-8,} \mathrm{all} \mathrm{the} \mathrm{measurements}$ have been carried out at $\mathrm{pH} 7.4$.

The enzymatic efficiency (i.e. percent of Choline $/ \mathrm{H}_{2} \mathrm{O}_{2}$ response ratio) was around $80 \%$. This percentage was higher than that obtained for the glucose biosensor $(32 \%)$, also taking into account that the choline oxidase reaction produces two molecules of $\mathrm{H}_{2} \mathrm{O}_{2}$ for each molecule of choline. A possible explanation of this result could be the polyanionic structure of Nafion, able to attract the positive charged molecules of choline, increasing its concentration near the enzymatic layer.

\subsubsection{Interferences study}

The interference signal due to the most common electrochemical interfering species was also evaluated. The signal for a fixed concentration of choline was compared with the current value obtained in the presence of the same concentration $\left(0.5 \mathrm{mmol}^{-1}\right)$ of the interfering species. The relative current signal gives a measure of the sensor selectivity. Results are summarised in Table 1 and show a high selectivity of the choline biosensor, probably due the low applied potential (i.e. $-50 \mathrm{mV}$ ). The interference due to ascorbic acid remains the same of what obtained with the PBmodified electrode, and there was no signal due to the uric acid. Negligible responses were obtained by cathecol and by acetylcholine, probably because of the spontaneous hydrolysis of this latter to give small amounts of choline.

\subsubsection{Reproducibility and repeatability}

Despite the additional deposition of the enzymatic layer to the PB modified SPEs, the inter-electrode reproducibility was comparable to that obtained for the electrodes modified with only PB. A total number of 42 choline biosensors (seven groups of six biosensors each) have been tested for their reproducibility. Each group was prepared the same day. The R.S.D.\% of the response to the choline of six different biosensors belonging to the same group was $6-7 \%$, while between biosensors of different groups, prepared and tested during a period of 9 months, was around $14 \%$.

The repeatability was evaluated using two choline biosensors and performing six successive calibration curves for each electrode. Results showed a R.S.D.\% of $2.5 \%$.

\subsubsection{Storage stability}

The storage stability of the biosensors in solution was evaluated at $4{ }^{\circ} \mathrm{C}$ and at $\mathrm{RT}$. The response to choline 20 $\mu \mathrm{mol} 1^{-1}$ of 20 biosensors, stored at $4{ }^{\circ} \mathrm{C}$ when not in use and tested every 2 weeks for 30 weeks showed an average decrease of $10 \%$ of the initial current value.

Further four electrodes were stored at room temperature during 4 weeks and tested every 2 days. The average activity was found to be $95 \pm 10 \%$ of the original one at the end of the period.

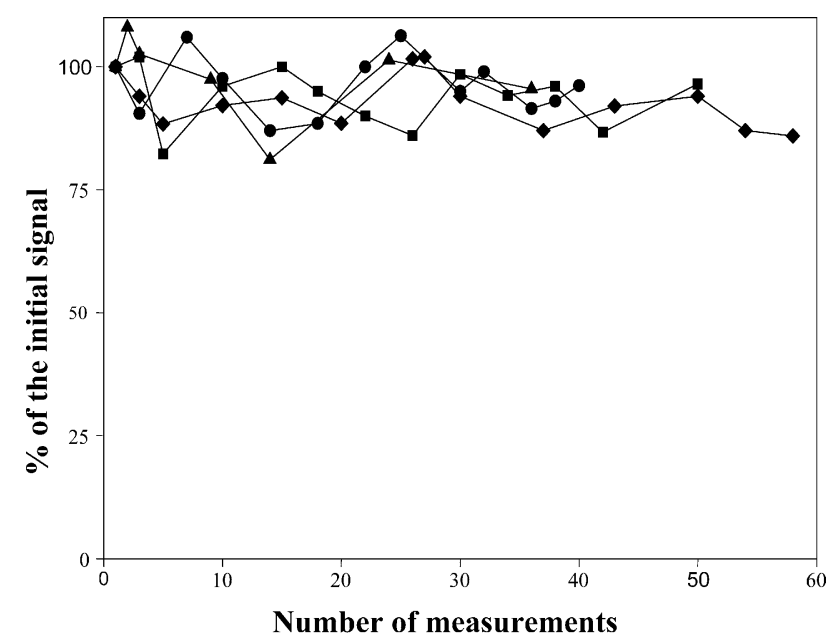

Fig. 6. Stability of choline biosensors $(n=4)$ during 6 months. Response to choline $20 \mu \mathrm{mol} \mathrm{l}^{-1}$ in $0.05 \mathrm{~mol} \mathrm{l}^{-1}$ phosphate buffer $+0.1 \mathrm{~mol} \mathrm{l}^{-1} \mathrm{KCl}, \mathrm{pH} 7.4$, applied potential $-50 \mathrm{mV}$ vs. the internal Ag pseudoreference electrode.

Table 1

Response of the choline biosensor towards interfering species $\left(0.05 \mathrm{mmol}^{-1}\right)$ in $0.05 \mathrm{~mol}^{-1}$ phosphate buffer $+0.1 \mathrm{~mol} 1^{-1} \mathrm{KCl}$, $\mathrm{pH} 7.4$

\begin{tabular}{llllll}
\hline Interfering specie $\left(0.5 \mathrm{mmol}^{-1}\right)$ & Choline & Ascorbic acid & Acetylcholine & Cathecol & Uric acid \\
\hline Relative activity $(\%)$ & 100 & 2 & 0.2 & 0.1 & No int. \\
\hline
\end{tabular}

Applied potential $-50 \mathrm{mV}$ vs. the internal Ag pseudoreference electrode. 
Fig. 6 shows the response occasionally obtained for choline $\left(20 \mu \mathrm{mol} 1^{-1}\right)$ of four different biosensors, which, during a period of 6 months have been routinely tested for choline and occasionally for $\mathrm{H}_{2} \mathrm{O}_{2}$. After a large number of measurements $(59,50,40$ and 37 , respectively) for each biosensor an average response decrease of $12 \%$ was observed.

\subsubsection{Operational stability}

The operational stability of the biosensors was evaluated keeping the biosensors continuously working

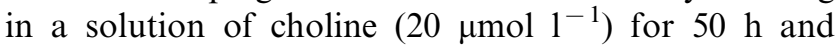
renewing the solution every morning. Also in this case the signal, continuously recorded, showed an average variation of $10 \%$.

\subsubsection{Acetylcholine biosensors}

This biosensor has been assembled to study the immobilisation of more than one enzyme. The enzyme AchE was coimmobilised with the choline oxidase enzyme as reported in the Section 2. The analytical characteristics can be summarised as follows: linear range between 5 and $100 \mu \mathrm{mol} 1^{-1}$; limit of detection 1 $\mu \mathrm{mol} 1^{-1}$; the equation of the calibration curve was $y=$ $6.28 x+0.95$, and $R^{2}=0.9999$, where $y$ was the current in $\mathrm{nA}$ and $x$ the concentration of acetylcholine in $\mu \mathrm{mol}$ $1^{-1}$. R.S.D. $\%$ ( $n=5$ different biosensors) was found to be up to $7 \%$. The sensitivity was $103 \mu \mathrm{A} \mathrm{mmol} 1^{-1}$ $\mathrm{cm}^{-2}$, and the enzymatic efficiency, i.e. the response of acetylcholine in respect to the same concentration of choline, was about $70 \%$.

The storage stability of these biosensors was similar to that of choline biosensors: after 21 weeks of storage in buffer at $4{ }^{\circ} \mathrm{C}$, the activity toward acetylcholine was still $100 \pm 10 \%$, and the same values were obtained after a 3 weeks storage at room temperature.

\section{Conclusion}

The new features of PB modified SPEs led to sensitive and reproducible probes for the detection of hydrogen peroxide. The use of PB resulted in a good selectivity towards electrochemical interferences. Moreover, the proposed novel PB modification procedure has brought to a stable layer even at basic $\mathrm{pH}$ values, overcoming the problems of operational stability and sensitivity in alkaline media, which still affect the use of this inorganic catalyst.

In addition, a new procedure for the immobilisation of enzymes on the surface of SPEs has been developed resulting in biosensors with improved characteristics of sensitivity and operational and storage stability. The choline biosensor obtained by cross-linking choline oxidase with glutaraldehyde and Nafion ${ }^{\circledR}$ onto the PB-modified SPE was found suitable for a stable and reproducible choline measurement in a range between 0.5 and $100 \mu \mathrm{mol} 1^{-1}$ within 9 months from its preparation. It has also shown the possibility to immobilise more than one enzyme on the surface of these modified sensors with similar performances in terms of storage stability, as in the case of the acetylcholine biosensor.

The results obtained with both the proposed methods of modification with PB and enzymes immobilisation, in our opinion, make these sensors an attractive alternative to the traditional biosensors.

\section{Acknowledgements}

This work has been supported by the European Community (ERBIC Project 15 CT 98 0906). A. Amine is grateful to the OPCW and to the University of Rome Tor Vergata for financial support.

\section{References}

Albareda-Silvert, M., Merkoci, A., Alegret, S., 2000. Configurations used in the design of screen printed enzymatic biosensors. A review. Sens. Actuat. B 69, 153-163.

Cagnini, A., Palchetti, I., Lionti, I., Mascini, M., Turner, A.P.F., 1995. Disposable ruthenised screen printed biosensors for pesticides monitoring. Sens. Actuat. B 24-25, 85-95.

Cass, A.E.G., Davis, G., Francis, G.D., Hill, H.A.O., Aston, W.J., Higgins, I.J., Plotkin, E.V., Scott, L.D., Turner, A.P.F., 1984. Ferrocene mediated enzyme electrode for amperometric determination of glucose. Anal. Chem. 56, 667-671.

Chi, Q., Dong, S., 1995. Amperometric biosensors based on the immobilization of oxidases in a Prussian Blue film by electrochemical codeposition. Anal. Chim. Acta 310, 429-436.

Collier, W.A., Lovejoy, P., Hart, A.L., 1998. Estimation of soluble Llactate in dairy products using screen-printed sensors in a flow injection analyser. Biosens. Bioelectron. 13, 219-225.

Deng, Q., Li, B., Dong, S., 1998. Self-gelatinizable copolymer immobilized glucose biosensor based on Prussian Blue modified graphite electrode. Analyst 123, 1995-1999.

Frew, J.E., Hill, H.A.O., 1987. Electrochemical biosensors. Anal. Chem. 59, 933A-944A.

Garjonyte, R., Malinauskas, A., 1998. Electrocatalytic reactions of hydrogen peroxide at carbon paste electrodes modified by some metal hexacyanoferrates. Sens. Actuat. B 46, 236-241.

Garjonyte, R., Malinauskas, A., 1999. Operational stability of amperometric hydrogen peroxide sensors, based on ferrous and copper hexacyanoferrates. Sens. Actuat. B 56, 93-97.

Garjonyte, R., Malinauskas, A., 2000. Glucose biosensor based on glucose oxidase immobilized in electropolymerized polypyrrole and poly $(o$-phenylenediammine) films on a Prussin Blue-modified electrode. Sens. Actuat. B 63, 122-128.

Garjonyte, R., Yigzaw, Y., Meskys, R., Malinauskas, A., Gorton, L., 2001. Prussian-Blue and lactate oxidase-based amperometric biosensor for lactic acid. Sens. Actuat. B 79, 33-38.

Gilmartin, M.A.T., Hart, J.P., 1995. Sensing with chemically and biologically modified carbon electrodes. A review. Analyst 120, $1029-1045$

Gorton, L., 1995. Carbon paste electrodes modified with enzymes, tissue, cells. Electroanalysis 7, 23-45. 
Grennan, K., Killard, A.J., Smyth, M.R., 2001. Physical characterisation of screen-printed electrode for use in an amperometric biosensor system. Electroanalysis 13, 745-750.

Hart, J.P., Wring, S.A., 1997. Recent developments in the design and application of screen-printed electrochemical sensors for biomedical, environmental and industrial analyses. TRAC 16, 89-103.

Hernandez, S., Palchetti, I., Mascini, M., 2000. Determination of anticholinesterase activity for pesticide monitoring using a thiocholine sensor. Int. J. Environ. Anal. Chem. 78, 263-278.

Iannello, R.M., Iacynych, A.M., 1981. Immobilised enzyme chemically modified electrode as an amperometric sensor. Anal. Chem. 53, 2090-2095.

Itaya, K., Akahoshi, H., Toshima, S., 1982. Electrochemistry of Prussian Blue modified electrodes: an electrochemical preparation method. J. Electrochem. Soc. 129, 1498-1500.

Itaya, K., Shoji, N., Uchida, I., 1984. Catalysis of the reduction of molecular oxygen to water at Prussian Blue modified electrodes. J. Am. Chem. Soc. 106, 3423-3429.

Jaffari, S.A., Turner, A.P.F., 1997. Novel hexacyanoferrate (III) modified graphite disc electrodes and their application in enzyme electrodes - part I. Biosens. Bioelectron. 12, 1-9.

Karyakin, A.A., 2001. Prussian Blue and its analogues: electrochemistry and analytical applications. Electroanalysis 13, 813-819.

Karyakin, A.A., Gitelmacher, O.V., Karyakina, E.E., 1995. Prussian Blue-based first-generation biosensor. A sensitive amperometric electrode for glucose. Anal. Chem. 67, 2419-2423.

Karyakin, A.A., Karyakina, E.E., Gorton, L., 1996. Prussian-Blue based amperometric biosensors in flow-injection analysis. Talanta 43, 1597-1606.

Karyakin, A.A., Karyakina, E.E., Gorton, L., 1998. The electrocatalytic activity of Prussian Blue in hydrogen peroxide reduction studied using a wall-jet cell with continuous flow. J. Electroanal. Chem. 456, 97-104.

Karyakin, A.A., Karyakina, E.E., Gorton, L., 2000. Amperometric biosensor for glutammate using Prussian Blue-based 'artificial peroxidase' as a transducer for hydrogen peroxide. Anal. Chem. $72,1720-1723$

Keesey, J., 1987. Biochemica Information, first ed., Boeringher Mannheim Biochemicals Publishers, Indianapolis, pp. 19, 20.

Moscone, D., D’Ottavi, D., Compagnone, D., Palleschi, G., 2001. Construction and analytical characterization of Prussian Blue- based carbon paste electrodes and their assembly as oxidase enzyme sensors. Anal. Chem. 73, 2529-2535.

Neff, V.D., 1978. Electrochemical oxidation and reduction of thin films of Prussian Blue. J. Electrochem. Soc. 125, 886-887.

Newman, J.D., White, S.F., Tothill, I.E., Turner, A.P.F., 1995. Catalytic materials, membranes, and fabrication technologies suitable for the construction of amperometric biosensors. Anal. Chem. 67, 4594-4607.

O’Halloran, M.P., Pravda, M., Guilbault, G.G., 2001. Prussian Blue bulk modified screen-printed electrodes for $\mathrm{H}_{2} \mathrm{O}_{2}$ detection and for biosensors. Talanta 55, 605-611.

Rippeth, J.J., Gibson, T.D., Hart, J.P., Hartley, I.C., Nelson, G., 1997. Flow-injection detector incorporating a screen-printed disposable amperometric biosensor for monitoring organophosphate pesticides. Analyst 122, 1425-1429.

Tothill, I.E., Newman, J.D., White, S.F., Turner, A.P.F., 1997. Monitoring of glucose concentration during microbial fermentation using novel mass-producible biosensor suitable for on-line use. Enzyme Microb. Technol. 20, 590-596.

Wang, J., Zhang, X., 1999. Screen printed cupric-hexacyanoferrate modified carbon enzyme electrode for single-use glucose measurements. Anal. Lett. 32, 1739-1749.

Wang, J., Pedrero, M., Sakslund, H., Hammerich, O., Pingarron, J., 1996. Electrochemica activation of screen-printed carbon strips. Analyst 121, 345-350.

Weißenbacher, M., Kalcher, K., Greschonig, H., Ng, W., Chan, W.H., Voulgaropoulos, A., 1992. Electrochemical behaviour of persulphate on carbon paste electrodes modified with Prussia blue and analogous compounds. Fresenius J. Anal. Chem. 344, 87-92.

White, S.F., Tothill, I.E., Newman, J.D., Turner, A.P.F., 1996. Development of a mass-producibile glucose biosensor and flowinjection analysis system for on-line monitoring during fermentation. Anal. Chim. Acta 321, 165-176.

Zakharchuk, N.F., Meyer, B., Hennig, H., Scholz, F., Jaworsi, A., Stojek, Z., 1995. A comparative study of Prussian-Blue-modified graphite paste electrodes and solid graphite electrodes with mechanically immobilised Prussian Blue. J. Electroanal. Chem. $398,23-35$.

Zhang, X., Wang, J., Ogorevc, B., Spichiger, U.S., 1999. Glucose nanosensor based on Prussian-Blue modified carbon-fiber cone nanoelectrode and an integrated reference electrode. Electroanalysis $11,945-949$ 